\title{
CREATIVE FIDELITY IN A CHANGING
}

\section{WORLD}

One of the earliest published writings that we have from the philosopher Maurice Merleau-Ponty is a review of Gabriel Marcel's Etre et Avoir. In his review Merleau-Ponty credits Marcel with the remarkable achievement of having taught us all to see in a new way. ${ }^{1}$ This new way of seeing, succinctly stated, is a seeing in which the seer remains concretely engaged with the subject matter, and hence eschews the enticing but abstract objective view. Merleau-Ponty used and considerably extended this new way of seeing in his own distinction between a thinking that remains informed by the structure of perception, and a thinking in which the mind soars above and takes an objective and general view of its subject.

In Marcel's prolonged effort to understand the human condition, it was the experience of the human body as "my body" that became pivotal and prompted him to call "incarnate being the central datum of metaphysical reflection".2 His effort to be faithful to this central datum has instilled in Marcel's thinking a tension that permeates the whole corpus of his work. It is a tension that arises from his insistence upon the importance of the individual incarnate person coupled with an equally strong insistence upon the need for an ultimate context ("Ultimate Recourse") that grants lasting meaning to the discourse among individuals. This tension, which is developed and epitomized in the term creative fidelity, is, for Marcel, more than a philosophical notion. It is the spiritual space wherein we live and learn to trust one another.

The topic I wish to investigate in this paper is whether and how the notion of creative fidelity, as developed in the philosophical and dramatic works of Marcel, might be seen as a constructive force

1Maurice Merleau-Ponty, "Etre et Avoir" in La Vie Intellectuelle, 45 (Oct. 1936): 98-109.

2This is the title given to the first essay in the collection Creative Fidelity, tr. Robert Rosthal (Noonday Press, New York: 1964). 
for responsible change. Can creative fidelity enable us to conserve and appropriate what has been achieved in the past and still enable us to be open to the newness so treasured by the proponents of progress? Can the adoption of the personal and political stance described by the term creative fidelity help us to bridge the rhetorical distance between those of us who fear change and those of us who fear the fear of change?

To begin, I will briefly review and reflect upon some of the central features of Marcel's notion of creative fidelity. Then I will suggest several ways in which this richly complex notion might be helpful for a contemporary understanding of change in politics, science and the arts.

One way to approach the question of creative fidelity is by way of Marcel's distinction between problem and mystery. Marcel uses the name problem to designate that kind of question, or unease, that allows a questioner to step back from the subject matter, to view it objectively, and to see the full contours of the matter at hand. Such problematic questions range from the trivial, "How many miles is it from Chicago to Boston?", to such highly complex tasks as developing sophisticated computer programs which can guide satellites into orbit or simulate certain features of human mental activity.

We are also acquainted, however, with certain questions or matters of unease that do not allow us as questioners to step back from the matter of the inquiry. The subject matter itself sometimes demands our immediate and sustained involvement as questioners. If, for example, I ask "What is the meaning of my life?" or if I ask whether I have a real friendship with my spouse, or even if I want to consider the personal meaning of my present effort to investigate the sense of creative fidelity, I have to allow the question to invade my own personal space, as it were; otherwise there can be no meaningful answer to the inquiry. Marcel uses the term mystery to designate this kind of question in which the very matter under investigation folds back over the questioner and demands that he or she refuse any clear-cut boundaries between him or herself and the matter for which a possible resolution is sought. The structure of the inquiry must be allowed to be formed by the kind of unease that seeks resolution. In the abstract, many topics can obviously be approached either as 
problems to be solved or as mysteries to be probed. In the concrete work of thinking, however, the kinds of inquiry, and what they can accomplish, turn out to be very different, as illustrated by Marcel's welldeveloped distinction between the body as thing and the body as "my body."

Perhaps, at bottom, all acts of consciousness are synthetic and involve, as Husserl argues in his Cartesian Meditations (\#17), a "belonging together inseparably" of elements that cannot be simply identified with one another. If this is so, then the peculiar "belonging together inseparably" that arises in our more personal acts, and which Marcel takes to be the order of mystery, requires its own specific investigation. In Marcel's descriptive analysis, the term mystery has nothing esoteric about it. The term is used to describe concretely the situation in which a person must, in order to remain truly personal, resist the temptation to abstract from the lived situation which always presents itself as a kind of "unity-in-difference" with what is other than oneself. It is these personal acts that constitute Marcel's realm of mystery. These acts include not only acts of love and hate, prayer and freedom, but also perception, memory, and feeling, when concretely attended to and not denatured by an objective or abstract approach.

The term "creative fidelity", combining as it does the ideas of creativity and faithfulness, of spontaneity and debt, expresses in summary fashion a prolonged effort by Marcel to uncover the ambiguous structure and fragile meaning of interpersonal relations. At the same time the term expresses Marcel's plea that these interpersonal relations be allowed to retain their experienced status rather than be reduced to problems to be solved.

Quite understandably, the clarification of the concept of creative fidelity in Marcel's thinking developed over a period of time, and like most of the central motifs of his thought, came to birth first in his dramatic works, and only later received express formulation in philosophical language. Typically in a Marcel play, the audience is led into the ordinary lives of two, three or four persons; one or more of these are, by reasons of choices they have made in the past, in some way dramatically alienated either from themselves or from the others. And typically the ending of the play leaves the resolution of the conflict in doubt. That is, the possibility of future harmony or of 
continued conflict is left unresolved, dependent upon the freedom of the individuals involved in the dramatic situation. Thus the audience, too, is left with the task of struggling to understand how the situation might resolve itself, left with the task of facing the issue of how and whether life can go on. The only thing that is clear is that no one of the characters can really live a full human life without deeply affecting and being affected by others. A pervasive and profound unity-indifference holds the characters together, whether in love or hate, or, more often, in a nuanced intermingling of both acceptance and rejection.

The dynamic tension between self and other that is revealed in a concrete description in which personal relations are allowed to retain their element of mystery, is manifest not only as a tension between one person and another. It appears in all genuinely personal human acts, and thus also in the way in which one relates or fails to relate meaningfully to one's own past or one's own future. There is not only an objective past to my life, but also a mysterious aging. Likewise, there is not only an objectively possible future, but also the human need to anticipate the future faithfully, that is, to trust that some possible future will actually be available. For this reason Marcel argues for a close relation between fidelity and hope. Creative fidelity has its place of application also in the task of integrating one truth or meaning into a whole life, whether the life of a single person or the life of a community. In fact, the furthermost reach of creative fidelity, and the most severe test of both the creativity and the fidelity, are found in the effort to think and affirm a relation between the living and the dead.

The particular force of creative fidelity, both as an instrument of evaluation and explanation, and as a habit of life, will be lost if we allow the idea of creative fidelity to be confused with certain related notions. Above all, creative fidelity must be set apart from the notion of constancy understood simply as the firm adherence to a position, such as a moral code or a dogma that one has been taught or has adopted. In contrast to such constancy, Marcel insists that when we are genuinely and personally involved with others it is necessary to maintain a degree of trust and respect for the others, and that this trust and fidelity is unthinkable apart from a certain spontaneity on our part. Fidelity, thus understood, is always directed toward another 
freedom; it is never directed toward oneself, nor toward some abstract principle. Only if this fidelity is directed toward and attentive to the personal presence of the other as person can it remain both faithful and creatively responsive to the needs of the other's freedom. Fidelity implies a free or spontaneous faith in oneself which seeks the spontaneity and trust of the other. Because it is a spontaneity that exists only in the call to another spontaneity, this creative fidelity is nothing less than a re-spontaneity that, when lived successfully, manifests itself as responsibility.

The discovery that personal spontaneity is intelligible only as responsibility, makes clear the tension that inhabits the idea of creative fidelity. Nevertheless, it is evident that without the element of my own personal freedom, and hence of my own personal presence, there is no creativity. And without the element of faithfully heeding and following the lead of the other, that is, without the element of my being placed in meaning, radically, by the other, there is no fidelity. In order to appreciate the full explanatory force of creative fidelity as an intellectual tool it is necessary to give full play to both the creativity and the fidelity.

If we do make room in our thinking for the exercise of the full scope of each part of this complex term, it becomes clear, I believe, that with the phrase creative fidelity Marcel is not merely describing a factual situation. He is addressing a lived, interpersonal encounter with a degree of concreteness that requires the reader to actually enter, to some degree, into the realm of mystery if he or she is to be able to comprehend the meaning of the experience being described. Thus even in the description of the structure of the encounter, the tension implicit in creative fidelity seems to spill out of the purely academic discourse and to make rather stringent demands upon those seeking to understand it. To be efficaciously understood, the idea of creative fidelity demands a kind of faith in the power of our minds to go beyond their own particular truths to the truths of others, and even to become intrigued by what Marcel has called the "intelligible background" of all particular truths.

One pervasive feature of Marcel's work, evident in both his philosophy and his plays, is an intense conviction that there is something profoundly out of order with our contemporary world. But 
this conviction is coupled with a reflective and determined refusal to give up hope for our world. He refers to our world as "broken," and gives one of his plays the title Le Monde Cassé. Repeatedly he laments the lack of reflection that seems to characterize our time and that has made us nearly blind to, or at least suspicious of, any explanatory effort other than the functional. Indeed, much of his work can be seen as an attempt to uncover the roots of the brokenness of our age, but this critique is persistently linked with the effort to restore and bolster the conviction that it remains possible for us to create a viable bond among people. During and beyond the two World Wars, Marcel came to share deeply the contemporary mistrust of reason's ability to discover or to establish such a bond. Nevertheless, he is by no means a prophet of doom. What is the wellspring of his hope?

One indication of the source of this hope can be seen, I think, in the fact that Marcel sometimes uses the words hope and fidelity as synonyms. This is especially the case when he speaks of the extreme locus of fidelity, that is, fidelity in the face of death. Death, especially the death not of oneself but of one's loved ones, appears to Marcel as a kind of test of fidelity. Love, he notes, always refuses to believe in the death of the beloved, even in the face of what appears as conclusive objective evidence.

To understand the intimate connection between fidelity and the experience of dying, we must recall that creative fidelity insistently brings together the non-interchangeable character of my own presence and the presence of personal otherness. Without my personal presence (and this is not to be equated with the muchcriticized subjectivity) and without the presence of the other, I have no entry into the human condition. My presence and that of the other person dwell inseparably together and in their openness to one another hold each other in existence. The test that the threat of death brings to this openness is the test of the meaningfulness and lovableness of the human person when the whole of my personal presence or the whole of the personal presence of the beloved is brought into question.

In one of the essays collected under the illuminating title Homo Viator, Marcel makes a distinction between "servir" and "servir a". He suggests that the latter phrase--to be serviceable, to be useful- 
-applies properly to things and to persons only when they are treated functionally. He suggests that the former--to serve--might be best illuminated by addressing the question "Whom or what do you serve?" to someone whom we have come to know personally. He goes on to say that if the person addressed would take "exception to such a question he would actually prove, by that very fact, that the deeper meaning of life had escaped him. It is clear, indeed, that all life is a service." 3

This bringing of the explanatory force of creative fidelity to bear on the wholeness of a life gives us a powerful, if troubling, place to relate the issue of creative fidelity to the theme of change in the arts, politics and sciences. If one can follow Marcel's inquiry all the way, and ask about the creative fidelity to the other when the whole of experience is brought into question, one has found a locus of inquiry where the possibility and structural meaning of change comes into frontal contact, as it were, with the question of the meaning of the very existence of politics, the arts, and the sciences. I am not suggesting that Marcel's work gives ready answers to questions about the ultimate meaning of politics, the arts and the sciences. I am, however, proposing that his notion of creative fidelity provides an interpretive space within which it makes sense to ask about the facticity of these human ways of comportment, and not merely about the meaning in this or that instance of their development. Fidelity can become, freely rather than with physical or logical necessity, a responsible force for change by making one attentive to the fact that there is a question about the whole as well as questions about the particular instances of politics, arts and sciences.

What kind of appearance this creative force will have in any community cannot be definitively forecast, but must be discovered in the very effort to achieve a "politics of meaning". 4 Its presence will, of course, be all the more difficult to discern and to foster when a society has become accustomed to limiting its political expectations to functional expertise, and its hopes to a functional harmony

3Gabriel Marcel, Homo Viator, tr. Emma Craufurd (NY: Harper \& Brothers, 1962), 125-6.

4I accept the term, with gratitude, from Michael Lerner, Editor and Publisher of Tikkun. 
embedded in such political instruments of change as policies and programs. Fair and effective policies and programs are surely necessary, but they belong primarily to the order of means. Creative fidelity invites reflection on the question of the suitability of our goals. It invites us to think of a "politics of meaning" in terms of a renewal of personal and communal presence, and renewal is not reducible either to revolution or to reformation. In the political order, perhaps more visibly than in the arts and sciences, the spilling over of the force of creative fidelity from the realm of knowledge to that of action is immediate. Fidelity, openly pursued, can provide assistance in the often difficult task of keeping theory and practice firmly united.

Understanding the political order in terms of creative fidelity would mean also an expectation of a certain tranquility and of a certain maintenance of personal space, even in the functional worlds of policies and programs. It would mean not only that the "personal is political" as suggested by some philosophers of liberation, but also that the political must remain personal. Thus it could give us a new awareness of the importance and perhaps even the centrality of the political action that is embedded in and manifested by the handshake, by the embrace, and by our taking time to converse with one another without purpose other than to be neighborly.

The presence of creative fidelity as a force for change in the arts and sciences could help to bring about an equally significant renewal. The working out of possible ways for this renewal will be an ongoing task and will not, of course, be a matter of producing something that can be completed and marketed. It will rather be a matter of creatively searching for ways to integrate artistic and scientific meanings into human existence without making either science or the arts subservient to ideological dogmas. A beginning might well be the rejection of the idea that either the sciences or the arts have an autonomy apart from the intelligible background which continually and mysteriously encompasses the whole. In this regard, it is necessary to acknowledge that there can be a totalitarianism of the mind, and even a possible totalitarianism of the sciences and the arts, that precedes and enlivens the totalitarianism we have come to know in the political order.

At this point it is perhaps helpful to return to Marcel's 
distinction between problem and mystery, and to notice that the meaning of wholeness is utterly different in the two realms. The wholeness proper to the problematic order is the wholeness of a system; the danger inherent in this wholeness is that of the manipulation of all truths and all possible forms of community. In the order of the problematic, only those objects and ideas deserve to be counted that can be made to stand up as present and identifiably functional: policies and programs, technological skills and achievements, cognitive science conceived as physics, systems of moral rules, language games.

In the order of mystery, on the other hand, each individual in the community manifests a wholeness deserving of respect. Each other person stands before me, and stands within the political economy, as one who is not really perceived but is rather abused if he or she is treated only as a function of the political order or as a part of a whole. And here I see no reason to give primacy to the negative formulation of Emmanuel Levinas. The face-to-face encounter with the other is surely not always and perhaps not even initially a meeting under the command: "Thou shalt not kill". 5 In the meaning revealed by creative fidelity the other stands up as the one who is to be trusted and admired. Furthermore, the meeting of the other is not a matter of finding an other who is needed for the sake of my coming to my own meaning and presence. The deeper meaning of the other as manifested in the structure of creative fidelity is his or her own beauty and wholeness. There is something both beautiful and revealing in Marcel's insistence that it is reflection upon the death of the "beloved other" rather than reflection upon my own death, that is most revealing of who we are as [political] persons. Remembering this, we might be more careful about which version of the American dream we choose to dream.

Whether a fidelity strong enough to build a viable bond among humans at the end of this tumultuous century is possible without commitment to an Absolute Thou may be a matter still to be learned. Marcel, it is safe to say, did find it necessary to make such a

5Emmanuel Levinas, Totality and Infinity, tr. Alphonso Lingis, Duquesne Studies, vol. 24 (Pittsburgh: Duquesne U. Pr.). See especially "Ethics and the Face," 197-216. 
commitment, as did his American contemporary Josiah Royce. At this time I wish to do no more than to raise the question of whether some such commitment, even if largely inarticulate, is not required for an efficacious human community. Work in this region of thought is inherently fragile, and those working here are always in danger of falling into a new dogmatism. Hence, the radical commitment to the personal presence of the other human person that is revealed and accomplished in the act of creative fidelity, is perhaps a first step toward a rebirth of hope at a time when a significant portion of our society has lost confidence in the political activity of governments. I say perhaps a first step, because I am convinced that even this first step must be made with an openness toward a more radical search for meaning. 6 Perhaps it is time to suggest that in political economy it is precisely the more ultimate values that we find and hold for one another that are in fact the nuts and bolts, as it were, which should attract our daily attention and concern. How else explain our apparent floundering in the questionable pursuit of ever-new experiences, and amidst the accumulation of ever greater techniques of satisfaction?

College of Holy Cross

CLYDE PAX

61 completely agree with Lawrence Cahoone's recent assessment that there is a speciousness and more than a little deceit in the contemporary search for consolation in the denial of ultimate questions. See his article "The Consolation of Antiphilosophy: Scepticism, Common Sense Pragmatism, and Rorty," Philosophy Today, 38(2) (Summer 1994): 204-224. 